\title{
COMMENT:
}

\section{The dual target strategy: a proposal to mitigate the risk of overtreatment and enhance patient satisfaction in rheumatoid arthritis}

\author{
Ricardo J. O. Ferreira' ${ }^{1,2}$, Mwidimi Ndosi ${ }^{3,4}$, Maarten de Wit ${ }^{5,6}$, Eduardo Santos 1,2,7, Cátia Duarte ${ }^{1,8}$, \\ Johannes W. G. Jacobs ${ }^{9}$, Pedro M. Machado10,11, Désirée van der Heijde12, Laure Gossec ${ }^{13,14}$, J. A. P. \\ da Silva ${ }^{1,8}$
}

\section{Affiliations:}

1 - Rheumatology Department, Centro Hospitalar e Universitário de Coimbra, Coimbra, Portugal.

2 - Health Sciences Research Unit: Nursing (UICiSA:E), Coimbra, Portugal.

3 - Department of Nursing and Midwifery, University of the West of England, Bristol, UK;

4 - Academic Rheumatology Unit, University Hospitals Bristol, Bristol, UK.

5 - Patient research partner, EULAR standing committee of People with Arthritis/Rheumatism in Europe (PARE), Zurich, Switzerland.

6 - Dept. Medical Humanities, Amsterdam University Medical Centre, Amsterdam Public Health (APH), Amsterdam, Netherlands.

7 - Escola Superior de Enfermagem do Porto. Instituto de Ciências Biomédicas Abel Salazar. Universidade do Porto. Porto, Portugal.

8 - Coimbra Institute for Clinical and Biomedical Research (iCBR), Faculty of Medicine, University of Coimbra, Portugal.

9 - Department of Rheumatology \& Clinical Immunology, University Medical Center, Utrecht, The Netherlands

10 - Centre for Rheumatology \& MRC Centre for Neuromuscular Diseases, University College London, London, UK

11 - Rheumatology Department, Northwick Park Hospital, London North West University Healthcare NHS Trust, London, UK

12 - Rheumatology department, Leiden University Medical Centre, Leiden, The Netherlands

13 - Sorbonne Universités, UPMC Univ. Paris 06, Institut Pierre Louis d'Epidémiologie et de Santé Publique, GRC-UPMC 08 (EEMOIS), Paris, France

14 - Rheumatology Department, AP-HP, Pitié-Salpetrière Hospital, Paris, France

Competing interests. None declared. 
With great interest we read the viewpoint from Prof. Landewé, ${ }^{1}$ calling for more caution, research, and debate regarding the risks of overdiagnosis and overtreatment in rheumatology. Strongly agreeing with the overall message, especially that "(...) overtreatment is hardly discussed but likely present", we would like to contribute to this discussion by raising an issue that touches base on two paradigms listed by Prof. Landewé: remission and evidence-based rheumatology.

There is now ample evidence that a substantial proportion (12 to 38\%) of patients with rheumatoid arthritis (RA) does not achieve the status of remission according to disease activity indices, solely because of a patient global assessment (PGA) score $>1$ (0 to 10 scale, $10=$ worst). ${ }^{2} 3$ If the elevated score on PGA does not reflect disease activity, additional immunosuppressive agents cannot improve the status of these patients, as inflammation is already essentially abrogated. Elevated PGA, therefore, may induce the risk of overtreatment when applying disease indices or Boolean-based criteria to define the treatment aim, which is remission or at least at low disease activity (LDA) according to current treatment recommendations. ${ }^{4}$ Naturally, patients who still report relevant disease symptoms despite the absence of significant inflammation need to be appropriately assessed and supported to address disease impact, but this probably calls for adjuvant interventions, rather than reinforcement of immunosuppressive therapy. ${ }^{6}$ This has led to our recent proposal that the management of RA should be guided by a dual treat-to-target strategy (dual T2T): one representing the control of inflammation (biological remission) and the other the control of disease impact (symptom remission). ${ }^{8}$ Remission of inflammation often also results in symptom remission, but not always. ${ }^{2} 8$ Given that the relationship between PGA and disease activity is not consistent, especially around the cut-offs of disease activity indices for LDA and remission, ${ }^{8}$ it is proposed that the definition of biological remission should not include PGA, but that it should be defined by the number of swollen and tender joints and CRP, i.e. 3-variable remission. This proposition is further supported by the evidence that, overall, PGA is driven by multiple factors beyond inflammation ${ }^{910}$, including non-inflammatory pain, limitation in physical function, fatigue, depression, and comorbidities, ${ }^{2} 8$ as well as by socio-economic and cultural factors. ${ }^{11}$ Recent research has demonstrated that patients vary enormously in their interpretation of the question and as many as $40 \%$ of them find scoring of PGA confusing. 1213 This is accrued by the existence of several different formulations of PGA, which, in itself, may influence the remission rate in 4.7 to $6.3 \%{ }^{14}$. 
Symptom remission, an important outcome from patient's perspective, ${ }^{15} 16$ would, in this proposal, be served better by an instrument capable of measuring and discriminating the underlying causes of on-going disease impact, so as to guide the selection of appropriate interventions. Currently, the best-suited instrument for this purpose seems to be the Rheumatoid Arthritis Impact of Disease score (RAID) ${ }^{17} 18$ with its seven domains, individually considered adequate to guide treatment decisions. ${ }^{18}$ Whatever the instrument chosen, treatment decisions must always be based on two-way communication and shared decision-making between the patient and the caring team. ${ }^{19}$

We believe that this novel strategy, i.e. dual T2T and the use of 3-variable remission and RAID, would significantly reduce the risk of overtreatment. Step-up of treatment strategies according to recommendations would still be used until biological remission is achieved. If, at this stage, symptom remission is not achieved, adjuvant therapy may be considered, according to the most affected domains of impact according to RAID. Actually, these domains of impact should be considered from the beginning, not only because patient well-being is a core objective of treatment but also because some of them, e.g. depression, may actually diminish the probability of achieving the biological target. ${ }^{20}$ It has been argued that "the remission criteria are designed for research and for optimum specificity, and not for use in treat-to-target schemes",21 but this does not preclude their frequent use in clinical settings. It has also been put forward that "most rheumatologists in practice do not need new instruments to decide which patients are most likely have residual disease and are in need of switching their treatment as opposed to patients with comorbidities that confound the interpretation of their RA symptoms". ${ }^{22}$ Prof. Landewé argues, conversely, that "sometimes (...) guidelines are too rigidly pursued by clinicians who may ignore the needs of individual patients". ${ }^{1}$ In fact, the EULAR recommendations for the management of RA state that treatment must be based on a shared decision with patients and that decisions on immunosuppressive treatment should take structural damage, comorbidities or contraindications into account. ${ }^{4}$ The risk of overtreatment would be further diminished if recommendations specifically address major aspects that may "confound" the practicing rheumatologist.

We believe that the proposal presented herein represents an important step forward in this direction. It also highlights the need to keep the patients' perspective and needs at the bull's eye of the treatment target, underlining the importance of an holistic approach to patient assessment and treatment, in order to achieve optimal results. ${ }^{19}$ In clinical trials, 
the improved relationship between the 3-variable disease index/remission criteria and disease activity would result in a more accurate determination of the actual efficacy and value of disease-modifying medications.

Additional evidence is needed to fully support this paradigm shift, namely by investigating whether exclusion of PGA negatively affects the relationship between remission and structural damage progression - the crunch of the matter, after all. Work is underway. ${ }^{23}$

\section{References}

1. Landewe RBM. Overdiagnosis and overtreatment in rheumatology: a little caution is in order. Ann Rheum Dis 2018 doi: 10.1136/annrheumdis-2018-213700 [published Online First: 2018/07/06]

2. Ferreira RJO, Dougados M, Kirwan J, et al. Drivers of patient global assessment in patients with rheumatoid arthritis who are close to remission: an analysis of 1588 patients. Rheumatology (Oxford) 2017;56(9):1573-8. doi: 10.1093/rheumatology/kex211 [published Online First: 2017/06/13]

3. Ferreira R, Ndosi M, Duarte $\mathrm{C}$, et al. Influence of patient global assessment on the disease activity assessment in patients with rheumatoid arthritis: a meteor crosssectional study [Abstract]. Ann Rheum Dis 2017;76(Suppl 2):1510-10. doi: 10.1136/annrheumdis-2017-eular.4695

4. Smolen JS, Landewe R, Bijlsma J, et al. EULAR recommendations for the management of rheumatoid arthritis with synthetic and biological disease-modifying antirheumatic drugs: 2016 update. Ann Rheum Dis doi: 10.1136/annrheumdis-2016-210715 [published Online First: 2017/03/08]

5. Smolen JS, Breedveld FC, Burmester GR, et al. Treating rheumatoid arthritis to target: 2014 update of the recommendations of an international task force. Ann Rheum Dis 2015;75(1):3-15. doi: 10.1136/annrheumdis-2015-207524 [published Online First: 2015/05/12]

6. de Hair MJH, Jacobs JWG, Schoneveld JLM, et al. Difficult-to-treat rheumatoid arthritis: an area of unmet clinical need. Rheumatology (Oxford) 2017 doi: 10.1093/rheumatology/kex349 [published Online First: 2017/10/14]

7. Santos EJF, Duarte C, Ferreira RJO, et al. Determinants of happiness and quality of life in patients with rheumatoid arthritis: a structural equation modelling approach. Ann Rheum Dis 2018;77(8):1118-24. doi: 10.1136/annrheumdis-2017-212934 [published Online First: 2018/04/08]

8. Ferreira RJO, Duarte C, Ndosi M, et al. Suppressing Inflammation in Rheumatoid Arthritis: Does Patient Global Assessment Blur the Target? A Practice-Based Call for 
a Paradigm Change. Arthritis Care Res (Hoboken) 2018;70(3):369-78. doi: 10.1002/acr.23284 [published Online First: 2017/05/26]

9. Nikiphorou E, Radner $\mathrm{H}$, Chatzidionysiou $\mathrm{K}$, et al. Patient global assessment in measuring disease activity in rheumatoid arthritis: a review of the literature. Arthritis Res Ther 2016;18(1):251. doi: 10.1186/s13075-016-1151-6 [published Online First: 2016/10/30]

10. Jacobs JW, Ten Cate DF, van Laar JM. Monitoring of rheumatoid arthritis disease activity in individual patients: still a hurdle when implementing the treat-to-target principle in daily clinical practice. Rheumatology (Oxford) 2015;54(6):959-61. doi: 10.1093/rheumatology/keu334 [published Online First: 2014/08/31]

11. Putrik P, Ramiro S. In wealthier countries, patients perceive worse impact of the disease although they have lower objectively assessed disease activity: results from the cross-sectional COMORA study. Ann Rheum Dis 2016;75(4):715-20. doi: 10.1136/annrheumdis-2015-207738 [published Online First: 2015/08/27]

12. Henriques M, Duarte C, Ndosi M, et al. "It can't be zero": a qualitative study of patients' perspective on patient global assessment in rheumatoid arthritis [abstract]. Ann Rheum Dis 2017;76(Suppl 2):112. doi: 10.1136/annrheumdis-2017-eular.6214

13. Hirsh J, Wood P, Keniston A, et al. Limited health literacy predicts patient confusion about patient global assessments of disease activity and rheumatoid arthritis model disease states. Arthritis Care Res (Hoboken) 2018 doi: 10.1002/acr.23692 [published Online First: 2018/06/29]

14. Ferreira RJO, Eugenio G, Ndosi M, et al. Influence of the different "patient global assessment" formulations on disease activity score by different indices in rheumatoid arthritis. Clin Rheumatol 2018;37(7):1963-69. doi: 10.1007/s10067018-4063-9 [published Online First: 2018/03/12]

15. van Tuyl LH, Hewlett S, Sadlonova M, et al. The patient perspective on remission in rheumatoid arthritis: 'You've got limits, but you're back to being you again'. Ann Rheum Dis 2015;74(6):1004-10. doi: 10.1136/annrheumdis-2013-204798 [published Online First: 2014/02/14]

16. Acebes C, Andreu JL, Balsa A, et al. Exploring the remission concept in rheumatoid arthritis with patients and rheumatologists: time for a new approach? Clin Exp Rheumatol 2017;35(5):816-22. [published Online First: 2017/05/19]

17. Gossec L, Paternotte S, Aanerud GJ, et al. Finalisation and validation of the rheumatoid arthritis impact of disease score, a patient-derived composite measure of impact of rheumatoid arthritis: a EULAR initiative. Ann Rheum Dis 2011;70(6):935-42. doi: 10.1136/ard.2010.142901 [published Online First: 2011/05/05] 
18. Ferreira R, Gossec L, Duarte C, et al. The Portuguese Rheumatoid Arthritis Impact of Disease (RAID) score and its measurement equivalence in three countries: validation study using Rasch Models. Qual Life Res (in Press).

19. Kiely PDW, Nikiphorou E. Management of rheumatoid arthritis. Medicine (Baltimore) 2018;46(4):216-21. doi: 10.1016/j.mpmed.2018.01.006

20. Matcham F, Davies R, Hotopf $M$, et al. The relationship between depression and biologic treatment response in rheumatoid arthritis: An analysis of the British Society for Rheumatology Biologics Register. Rheumatology (Oxford) 2018;57(5):835-43. doi: 10.1093/rheumatology/kex528 [published Online First: 2018/02/16]

21. van Tuyl LHD, Boers M. The controversy of using PGA to define remission in RA. Nat Rev Rheumatol 2018;14(4):245. doi: 10.1038/nrrheum.2018.36 [published Online First: 2018/03/22]

22. van Tuyl LHD, Boers M. Rheumatoid arthritis: Remission - keeping the patient experience front and centre. Nat Rev Rheumatol 2017;13(10):573-74. doi: 10.1038/nrrheum.2017.139 [published Online First: 2017/09/01]

23. Ferreira RJO, Welsing PMJ, Gossec L, et al. The impact of patient global assessment in the definition of remission as a predictor of long-term radiographic damage in patients with rheumatoid arthritis: protocol for an individual patient data metaanalysis. Acta Reumatol Port 2018;43(1):52-60. [published Online First: 2018/03/31] 